\title{
Optimization and Reform of Sewage Treatment Process Upgrade Based on Circular Economy
}

\author{
Shen Hengxia ${ }^{1,2, a}$ \\ ${ }^{1}$ College of Environmental Science and Engineering, Ocean University of China Shandong Qingdao \\ 266000, China \\ ${ }^{2}$ Rizhao Environmental Protection Bureau Shandong rizhao 276800, China \\ a893458480@qq.com
}

Keywords: cyclic economy, wastewater treatment, process modification, diatomite

\begin{abstract}
This paper takes cyclic economy as research background, adopting diatomite to enforce A2 /O process and to make treatment study, using $\mathrm{A} 2$ /O process testing equipment to simulate the running conditions of $\mathrm{A} 2 / \mathrm{O}$ process in wastewater treatment plant, and adjusting the index parameters in A2/O testing equipment to make it reach optimum operational status; with present amount of inlet water, the best process control parameters are: under the circumstance where the ratio of anoxic zone and system's total volume is $1: 3$, the dissolved oxygen concentration staying at $3 \mathrm{mg} / \mathrm{L}$ or so, and the inner recycling ratio is $200 \%$, it is feasible to reform to $\mathrm{AO} / \mathrm{denitrification}$ process after adjusting previous aeration tank. This paper proposes to optimize A2/ denitrification process into BdarePnho process with both the concentration of total nitrogen and the ammonia nitrogen concentration in the effluent under $10 \mathrm{mg} / \mathrm{L}$, and great nitrogen removal effect has been achieved. The optimal process parameter combination in the expansion process is:
\end{abstract}

\section{Introduction}

During recent years, as Chinese industrialization process is accelerating large-scale production is aggravating, the unreasonable industrial structure leads to an economic development model with high consumption and high pollution in many areas, which prevents resources from optimal configuration and causes waste; therefore, optimal development of industrial cluster cannot be formed. Especially for Siping area in the source area of Liao River, the industrial development of industry will bring continuous pressure to the environment, with wastewater discharge increasing and pollutant emission rising; the total amount of pollutant in the water environment is close to saturation severely $^{[1,2,3]}$.

As a mode of economic development conforming to sustainable development idea, cyclic economy has become an effective path to solve the conflict between economic development and resources and environment in many countries. Under the cyclic economic development model, the adjustment and upgrading of industrial structure has been endowed with new connotation ${ }^{[4,5]}$. To protect water environment and to realize sustainable economic growth ${ }^{[6,7]}$, it is rather important to adopt composite water environment improvement policies including new techniques of wastewater treatment and new techniques of sludge treatment. How to predict and evaluate the economic influence of environment under composite water environment policies is urgent to be solved.

This paper aims to reform the previous aeration tank into AO system to get denitrification effect without increasing investment of capital construction. Mathematical model simulation is taken to inspect its feasibility and determine the optimal operation parameters in the system after transformation. The results show that, as for Tianshan Plant, with present amount of inlet water, the optimal process control parameters are: the ratio of anoxic zone and system's total volume is 1:3, the dissolved oxygen concentration staying at 3mg/L or so, and the inner recycling ratio is $200 \%$. After transformation, the effluent COD concentration doesn't change much, but the concentrations of ammonia nitrogen and total nitrogen in the effluent decrease greatly; the concentration of effluent can reach the emission standard stipulated by the nation. 


\section{Experiment design and method}

The main body of process experimental facility adopts A2/O process simulation equipment, with material of organic glass. The front end is regulating tank, which can adjust water volume and play as primary sedimentation tank. The equipment is $81 \mathrm{~cm}$ in length, $43 \mathrm{~cm}$ in width and $61 \mathrm{~cm}$ in height. The effective depth is $54 \mathrm{~cm}$, and effective volume is 195L. The inner part of equipment adopts glass pane to divide into 3 cells, which are anaerobic tank, anoxia tank and aerobic tank with the volume ratio of 1:1.5:5.

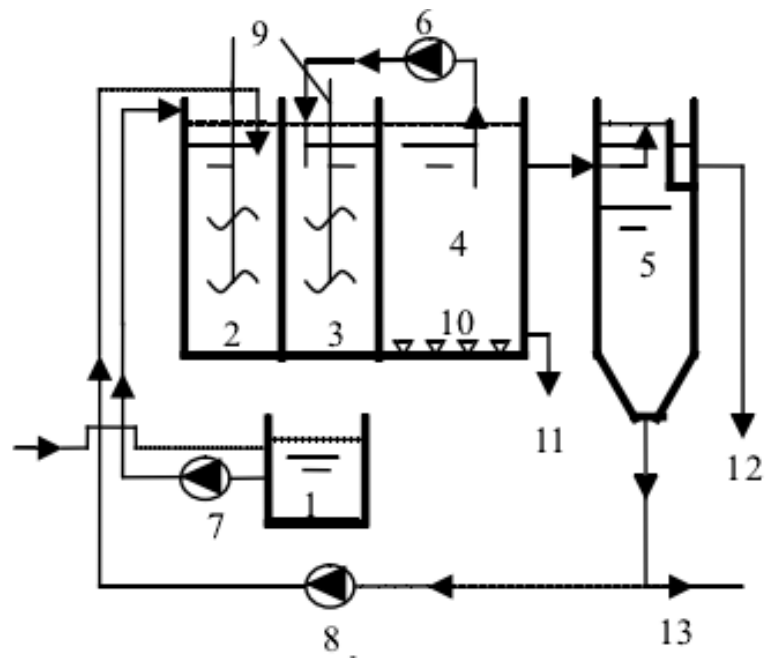

. Adjusting tank 2. anaerobic tank 3. Anoxia tank 4. Aerobic tank 5. Radial-flow sedimentation tank 6. Mixed liquor backflow peristaltic pump 7. Water pump 8. Sludge reflux pump 9. Stirring apparatus 10. Aerator 11. Drain pipe 12. Exhaust water pipe 13. Sludge withdrawal pipe

Figure $1 \mathrm{~A} 2 / \mathrm{O}$ simulation equipment of water plant

Holes are left on the splitter plate to ensure the water power connection between tanks. Stirring devices are set in the anaerobic tank and anoxia tank; there is micropore aerating apparatus in aerobic tank, through which aerator pipe is connected with aerator pump with air flow meter at the joint to adjust aeration rate. Meanwhile, mixed liquor reflux pump and sludge reflux pump are set to make mixed liquor and sludge flow back. Radial-flow second sedimentation tank is set at the end, with water flowing in at the center and flowing out all around; the diameter is $33 \mathrm{~cm}$, effective depth $37 \mathrm{~cm}$, effective volume 55L and sludge pit height $25 \mathrm{~cm}$. The experiment equipment can be seen in Figure 1.

The analysis and detection of effluent quality is conducted throughout the experiment procedures, which is the judgment criteria of the success of experiment, the normal operation of each procedure and the selection of the best running condition. The water for experiment is sanitary sewage of Hebei Agricultural University. The sewage is pumped by submersible sewage pump and transported into the indoor tank in storage. Thus, the water for experiment is all provided by the sewage stored in the tank. It is required that we should pump for several times during the experiment, therefore, the quality of water fluctuates in a large extent and the indicators are a little bit unstable. As shown in table 1:

Table1. Effluent quality during the experiment

\begin{tabular}{llcl}
\hline Test Items & CODcr/(mg/L) & $\mathrm{NH}^{+}-\mathrm{N} /(\mathrm{mg} / \mathrm{L})$ & $\mathrm{TP} /(\mathrm{mg} / \mathrm{L})$ \\
\hline Range of Measured Value & $245 \sim 631$ & $14.2 \sim 38.7$ & $5.6 \sim 19.2$ \\
\hline Average Value & 438 & 26.5 & 12.4 \\
\hline
\end{tabular}

\section{A2/0 simulation test process operation and parameter testing}

\section{A2/0 process start and sludge cultivation}

COD in sanitary sewage is small, which can't reach the required concentration in sludge cultivation $^{[8,9]}$. Therefore, the sewage used during sludge cultivation is the mixture of sanitary sewage and artificial water. The sewage is stored in the aqua storage tank and 24 hours continuously 
deliveried by peristaltic pump. During cultivation period, the water quality fluctuates widely. The water temperature is $17 \sim 24^{\circ} \mathrm{C}$ in the process of sludge cultivation, and the mean temperature is $20.5^{\circ} \mathrm{C}$. We observe the activated sludge in the tank every day, and look into sludge settling ratio at the same time. We also measure CODcr、 $\mathrm{NH}^{+}-\mathrm{N}$ as well as TP in the water at regular intervals, and then conclude the observed changes of sludge growth, and organize the measured data. The microorganisms which are the most suitable for the enviroment get the full growth and rapidly multiply to form bacterial colony. While the microorganisms which are not suitable for the enviroment suffer from elimination. From the macro perspective, the treatment efficiency of the activated sludge on sledge is getting better and better. The bad and dead mud used in inoculation gradually change into activated sludge which is applied to process sewage with specific water quality. The following figures show the change of sludge setting ratio during sludge cultivation. And it is more intuitive to see the variation trend of sludge through the following figures.
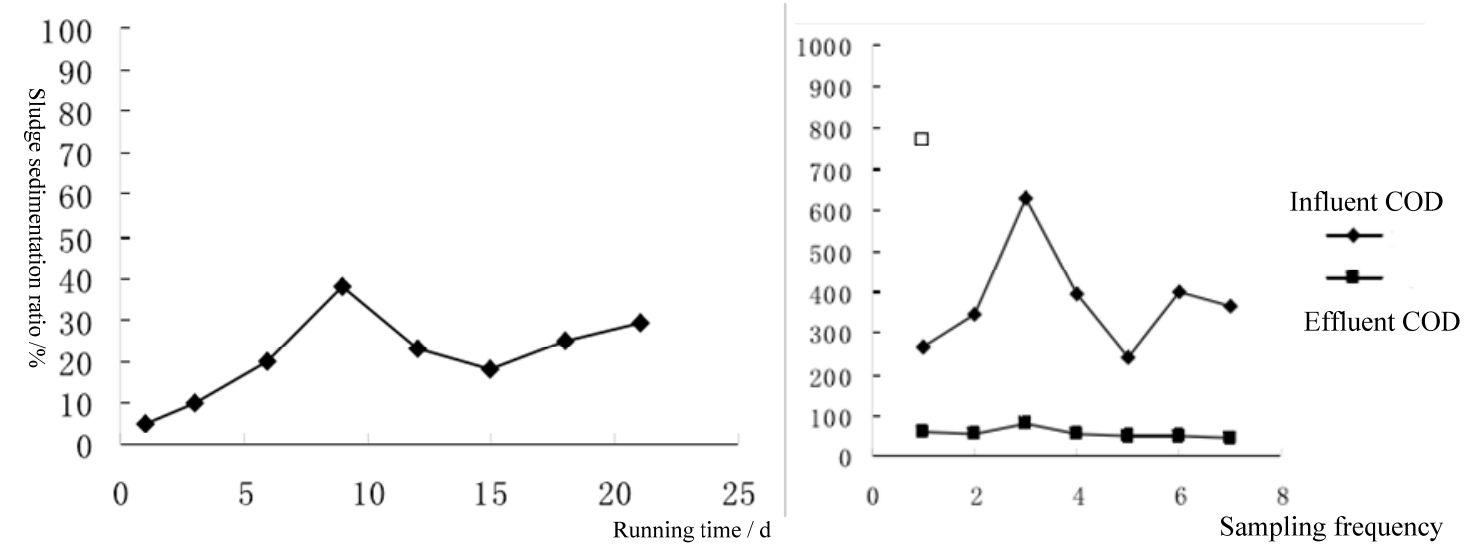

Fig.2. Changing curve of sludge settling ratio in the process of sludge cultivation

Fig.3. Changing curve of CODcr effluent concentration in the process of sludge cultivation

Through observing CODcr、 $\mathrm{NH}^{+}-\mathrm{N}$ and TP in the water sample, we can find the effluent quality a little bit unstable during the initial stage of sludge cultivation. Moreover, the indicators float largely and the removal rate of pollutants in the water is kind of low as well. As the sludge cultivation going with a swing, the effluent quality is even more stable and presents a trend of gradually increasing, and finally remains stable in a certain range.

As shown in fig.3, the mean concentration of CODcr in the effluent is $438 \mathrm{mg} / \mathrm{L}$. At the beginning of continuous water intaking, the activity of sludge is kind of weak, and the settling ratio is relatively low as well. As a result, the removal rate of sludge on CODcr is not high, which is only about $77 \%$. In the following five day, the growth of microorganism begins to speed up. CODcr, which is regarded as the source of carbon needed by the growth of microorganism, is absorbed in a large amout, and the removal rate of CODcr presents a steadily rising trend.

On the sixth day, CODcr in the water rises sharply because of the failure of operation. A large amount of carbon source also leads to the rapid growth of microorganisms. And aeration rate seems to be slightly insufficient. In the water, the anaerobic reaction of sludge happens, which makes the sludge black and its activity decreased. At the same time, the concentration of the effluent CODcr is larger, but the removal rate of CODcr reaches to about $87 \%$. After adjusting for a period of time, the sludge returns to be normal, and the removal rate declines slightly. And then, after changing the water, the removal rate steps down and the activated sludge gradually stabilizes at around $87 \%$.

\section{Analysis of the influence of A2/0 system process parameters on the component of sewage quality}

Before the reconstruction and extension of denitrification process in sewage treatment plant, we should determine the volume of nitrification tank and denitrification tank in advance ${ }^{[10]}$. The 
conventional method is to obtain the volume of anoxic section and aerobic section through calculation. And the calculating methods are as follows:

(1) Calculating the volume of the nitrification tank $\left(V_{N}\right)$ on the basis of sludge age and the volume required by oxidation of organism (remove BODS)

$V_{N}=\frac{Y Q\left(S_{0}-S_{e}\right) \theta c}{X\left(1+K_{d} \theta_{e}\right)}$

In the formula, Y- the sludge yield coefficient (kg VSS g BODS (removal)); Q-sewage rate (m3zd); $\mathrm{S}_{0}$, Se- the BODS concentraction of in-take and out-take water $(\mathrm{mg} / \mathrm{L})$; $\mathscr{A}$ - sludge age (d); Kdendogenous respiration coefficient $\left(\mathrm{d}^{-1}\right)$; X- the concentration of mixed liquor volatile suspended solids (mg/L).

Calculating and designing sludge age on the basis of required nitrification efficiency or the concentration of effluent ammonia and nitrogen:

$\theta_{c}=\frac{K_{N}+\left(1-E_{N}\right)\left[N H_{4}^{+}-N\right]_{0}}{\mu_{\max }\left(1-E_{N}\right)\left[N H_{4}^{+}-N\right]_{0}}$

According to figure 4 and figure5, with the increase of sludge age SRT, the number of heterotrophic microorganism and the MLSS in aerobic tank and anoxic tank increases accordingly; since nitrobacteria can only grow by making use of the aeribic tank volume in the system, and its growth is kind of slow. Therefore, the occur of denitrification in the system requires a bit langer SRT, which can be proved by the changing curve of the concentration of nitrogen, nitrate nitrogen and autotrophic microorganism. Only when SRT is close to 3 days begins the nitrification effect in the system. If SRT is less than 4 days, nitrobacteria will get loss in the reaction tank, which makes that the nitrification reaction can not be carried very well. In this way, the removal of ammonia nitrogen will get worse gradually. Meanwhile, the dissolved organism in anoxic tank will increase significantly, which is mainly because that the major way to remove the organism in anoxic tank is denitrification effect. Moreover, when RST is really small, the nitrification can not occur completly and the concentration of nitrate nitrogen is low, which means that there is not enough electron receptor refluxing to the anoxic zone and the organism in anoxic zone can not degradate sufficiently. Thus, lots of organism will move from the anoxic zone into aerobic zone, which makes the removal rate of organism decline and the concentration of effluent oranism increase. With the increase of sludge age, the degree of nitration will become higher. In addition, the oxidation of ammonia nitrogen in sewage is more complete and its concentration is lower as well. When SRT is more than 4 days, sludge age has almost no effect on the concentration of nitrate nitrogen in anoxic tank. With the increase of sludge age, the concentration of nitrate nitrogen in aerobic tank will rise accordingly. In contrast, the concentration of the organism in anoxic tank and aerobic tank in the system will decrease. However, with the increase of sludge age, especially after being more than 10 days, sludge age has little effects on the concentration of organism, nitrate nitrogen and ammonia nitrogen in the system. According to the curve graph of sludge age on particulate non-degradable organism, as the increase of sludge age, its concentration in the system is a rising trend as well. The main reason is as follows: with the increase of sludge age in the system, microorganism will age, and the number of dead microorganism will increase, which lead to form particulate matrix and cell residues, so that the proportion of non-active components in the sludge will increase. Therefore, the change of sludge age has little effect on particulate organic nitrogenous, dissolved organic nitrogenous and particulate non-degradable COD. 


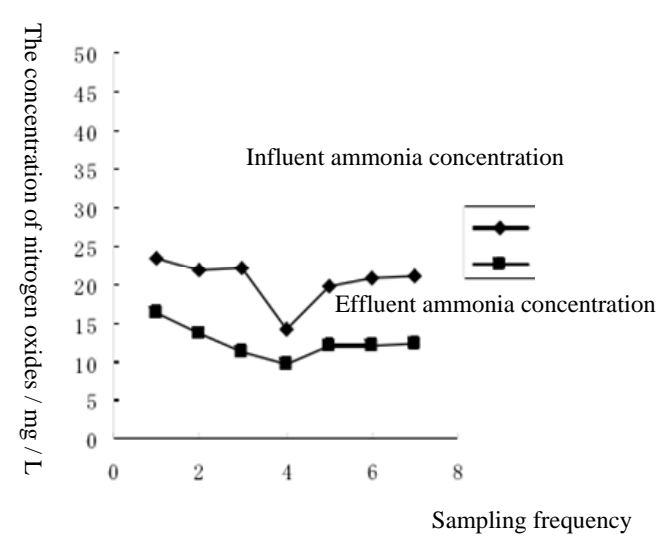

Fig.4.Variation of effluent nitrogen and oxygen concentration in the process of sludge cultivation

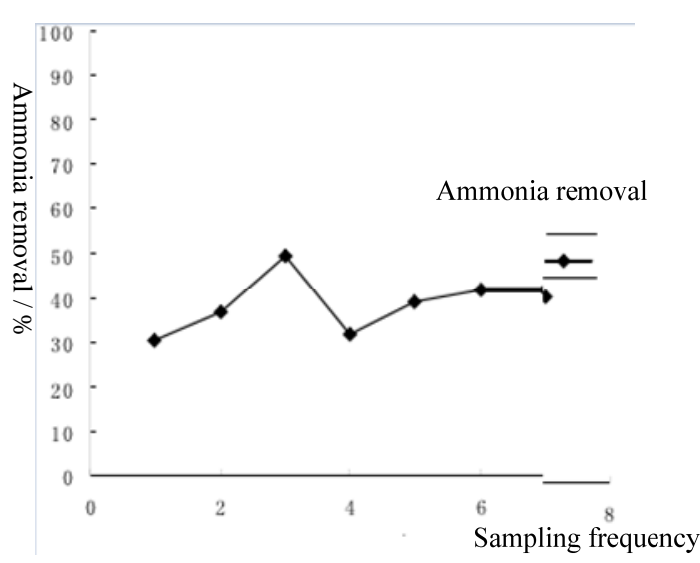

Fig.5. Variation of effluent nitrogen and oxygen removal efficiency in the process of sludge cultivation

In aerobic tank, the number of the plates of autotrophic microorganism and heterotrophic microorganism actually has nothing to do with the return sludge. The reason is that organic concentration is almost completely removed with the respective of the influent. In figure 4 and figure 5 , under the situation that the microorganism is in certain, adjusting reflux ratio can only change the speed of microorganism moving from aerobic tank into anoxic tank. Thus, the concentration of heterotrophic bacteria in anoxic tank raises, furthermore, the hydrolysis of particulate refractory organism and organic nitrogen increase in anoxic tank as well. In anoxic tank, it shows that the concentration of the two groups decrease with the increase of reflux ratio. Meanwhile, with the increase of reflux ratio, denitrification effect enhances correspondingly, and the concentration of nitrate nitrogen in aerobic tank decreases. The concentration of the other organism in aerobic tank are less affacted by reflux ratio. This mainly refers to the increase of reflux ratio. Under the situation that the microbial biomass is in certain in the system, the dissolved organisms in aerobic tank are removed, and the amount of residual organism in the effluent only reflects the equilibrium between organism degradation and the organism released by the decomposition of microorganism's own death. Through the adaptive process for several days and the impact of the significant increase of CODcr concentration, the content of TP in the effluent decreases significantly, and the removal rate reaches $38 \%$ as well. After the adjustment of water quality, the concentration of TP in the effluent will rise slightly, and meanwhile, the removal rate of TP is stable at about 50\% gradually after a period of ups and downs. In summary, the removal rate of TP is not as ideal as $\mathrm{NH} 4^{+}-\mathrm{N}$.

Organism content in the effluent

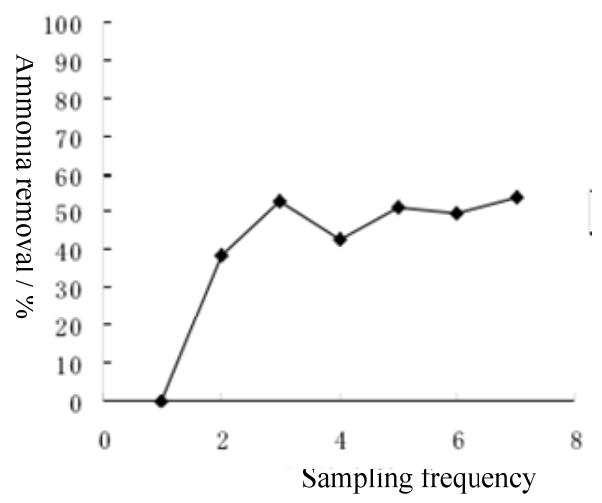

Fig.6. Variation of TP removal efficiency process of sludge cultivation

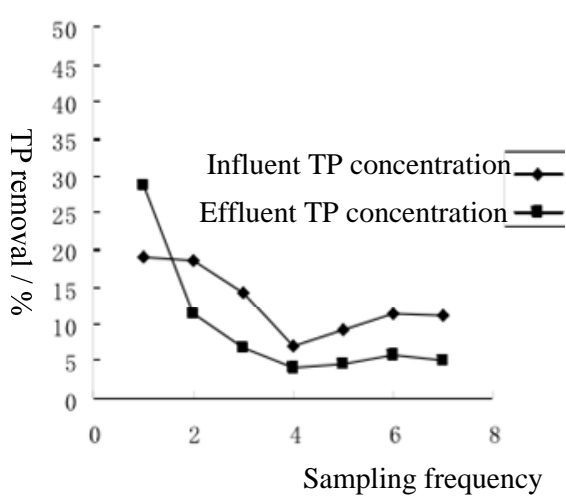

Fig.7. Variation of effluent TP concentration in the in the process of sludge cultivation 

treatment plant

\section{Biological denitrification reform with constancy of volume}

The micro aeration or no aeration in the front of the reaction tank contribute to the formation of anoxic zone and lead to denitrification effect. In addition, we add a mixed liquid recirculation system, so as to offer nitrate nitrogen for denitrification. It is shown in figure 8.

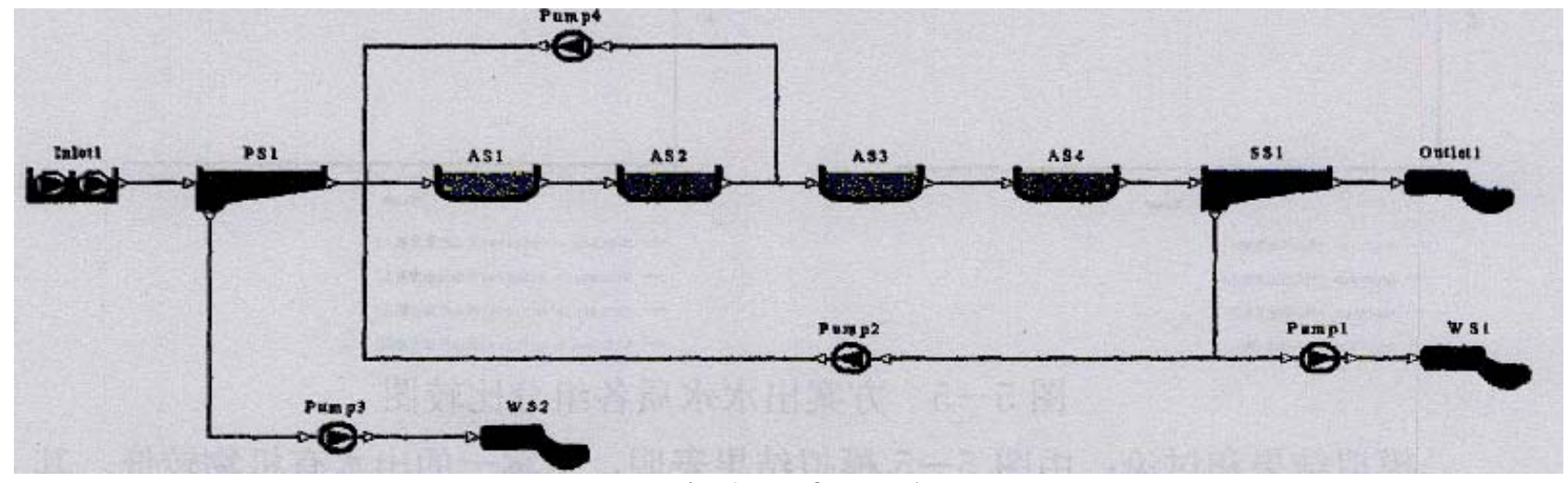

Fig.8. Reform plan

As shown in figure 9, if the volume ratio of anoxic tank and aerobic tank increases, the total simulated effluent COD is almost not affected by the volume increase of anoxic tank. While, as for the effluent concentration of $\mathrm{TN}$, with increase of the expanded volume of anoxic tank, the concentration of total nitrogen in the effluent decreases summarily. However, when the volume ratio of aerobic tank and anoxic tank is between 1:4 and 1:3, the concentration of total nitrogen in the effluent produces less decrease. When the volume ratio of aerobic tank and anoxic tank exists between 1:3 and 1:2, there is a rapid decline in the trend at this time. Then, when the volume of anoxic tank increases again, the concentration of nitrogen in the water still shows a downward trend, but the decreased range is not wide. When the expanded volume of anoxic tank is small, the concentration of ammonia and nitrogen in the effluent is higher. The main reason is that when the volume of anoxic tank is small, denitrification is weak due to the short hydraulic residence time. However, at present, the organic load in Tianshan Sewage Plant is hign, so that the organic load in aerobic tank is still a little bit high. The heterotrophic bacterium grows kind of rapidly, while autotrophic bacterium's growth is inhibited. When the expanded volume of anoxic tank continues to increase, the concentration of ammonia and nitrogen will decrease. However, when the volume ratio of anoxic tank and aerobic tank is more than 1:2, in the case of constant volume of aerobic tank, the increase of volume of anoxic tank will lead to the slow decrease of the concentration of ammonia and nitrogen. At this time, the capital expenditure of structures will have a huge increase, which causes unnecessary waste. As a result, through comparing the relationship between volume of anoxic tank and the effluent concentration of total fluoride, ammonia and nitrogen as well as nitrate nitrogen, we would like to keep the volume ratio of anoxic tank and aerobic tank stay in 1:2, which is used as the volume ratio of expansion process. 

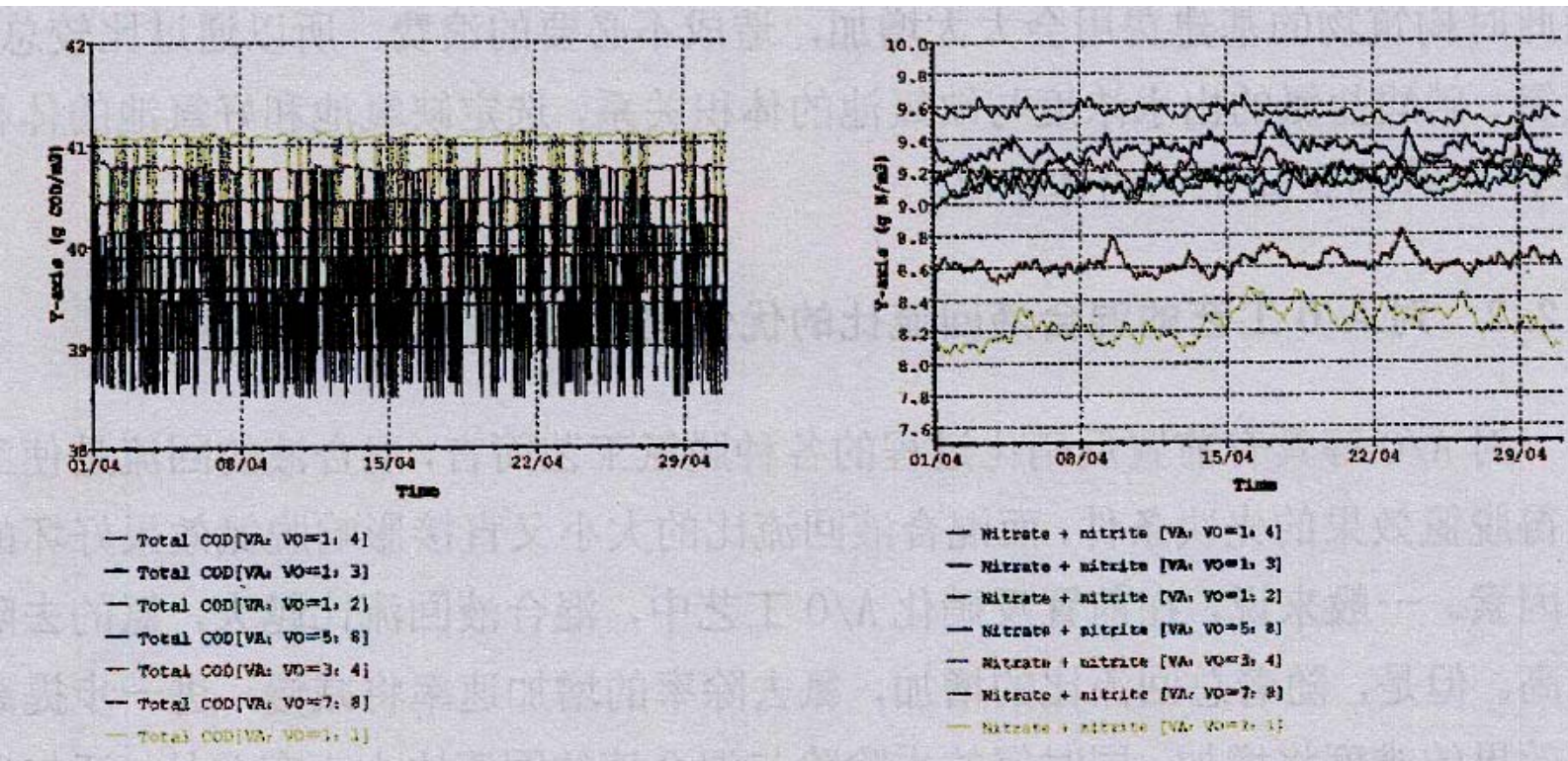

Fig.9. Contrast diagram of the influence of volume ratio of aerobic tank and anoxic tank on the quality of effluent

If we increase internal return ratio, the concentration of effluent COD will show a downward trend. In general, when other conditions meet the process of nitrification and denitrification in the system, the change of internal return ratio will have little influence on effluent COD and ammonia nitrogen, however, it has different effects on nitrate nitrogen and total nitrogen. When internal return ratio is between 2 and 3, especially when it reaches 3, a great amount of nitrate nitrogen will return to anoxic tank, so that the electron acceptor in anoxic tank is no longer the constraint of denitrification process. In addition, the denitrification enhances and the denitrification effect increases significantly. However, with further increase of internal return ratio, the promotion of denitrification ability is not obvious. At the same time, due to the increase of internal return ratio, the operating cost of the system rises as well, which leads to the diseconomy of the operation in the system. Therefore, for the process of denitrification reform of sewage treatment plants, it is reasonable to keep internal return ratio at 3.
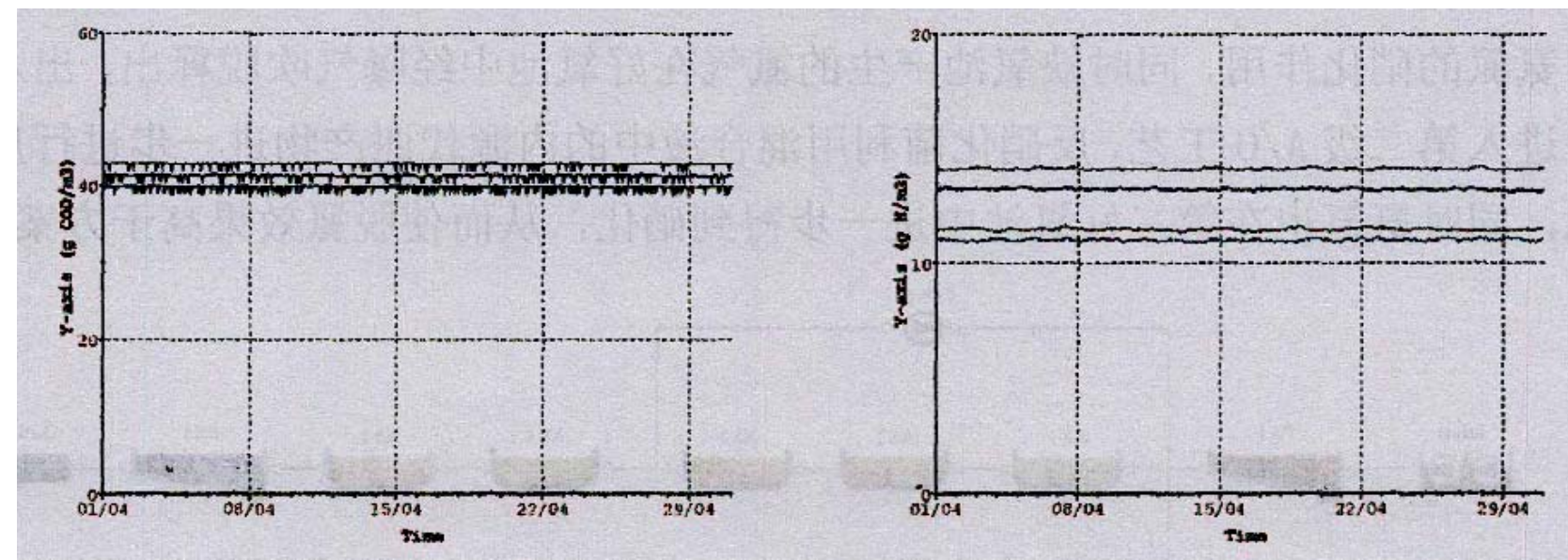

Fig.10. Contrast effect diagram of the influence of internal return ratio on the quality of effluent

\section{Summary}

Sewage and sludge treatment can not only reduce the emission of pollution material in the water to improve the water enviroment, but also achieve the recycling of resource and energy, which reduces greenhouse gas emissions. In order to scientifically analyze the influence of sewage and sludge treatment on the enviroment and social economy, this thesis constructs a comprehensive evaluation model with dynamic optimization. It simulates the performance of A2/O process in sewage treatment plant by A2/O process tester, and adjusts the various index parameters of $\mathrm{A} 2 / \mathrm{O}$ process tester, so that 
it will achieve the best operating conditions. The research indicates that the quality of $\mathrm{A} 2 / \mathrm{O}$ process effluent which is strengthened by diatomite is improved obviously. Moreover, the effect of the treatment of pollution material in the water is more obvious, and there is no need to add more handle structures, which saves both resources and funds. It will produce less pollution to the enviroment and be suitable for the upgrade and reform of urban sewage treatment plants.

\section{References}

[1] Chae, S.R. and Shin, H.S. Effect of condensate of food waste (CFW) on nutrient removal and behaviors of intercellular materials in a vertical submerged membrane bioreactor (VSMBR).Bioresource Technology, 2007, 98(2),p373 379.

[2] Fan Yuejin. Brief Comment on Theoretical Foundation of Circular Economy[J]. Journal of Shandong University of Technology (Social Science Edition), 2005,21(2), p10-17.

[3] Gu Jinchuan, Jiang Wenju, Yong Yi. Sludge Treatment and Resource Recovery of Urban Sewage Plant. Beijing: Chemical Industry Press, 2008, p 29-30.

[4] He Wangyang, Yang Min, Liu Furao et al. Experimental Study of Anaerobic Fermentation Gas Properties of Excess Sludge. An’hui Agricultural Science, 2013,41(11),4988 4990.

[5] Jia Shuting, Zhang Dong, Zhao Jianfu et al. Research Progress of Different Pretreatment Methods of Promoting Anaerobic Fermentation of Primary and Excess Sludge to Poduce Biogas. Chemical Progress, 2013,32(1),p193 197.

[6] Li Lin. Current Situation and Trend of Anaerobic Digestion Technology Development and Application of Sludge. China’s Environmental Protection Industry, 2013,p 17-22.

[7] Ji Kunsen. Principle and Application of Circular Economy. An'hui: An’hui Science and Technology Press, 2004,p 589-596.

[8] Ji Min, Huo Jinsheng, Hu Zhenquan et al. Research and Application of Mathematical Model of Activated-Sludge Method. China’s Water Supply and Drainage, 2001,17(8), p18 22.

[9] Zhang Liqiang, Yang Gang, Jia Ruizhen. Process Comparison of Sewage Treatment Plant in Zedang Town of Shannan Area in Tibet[J]. Shanxi Architecture, 2010,(7), p173-174.

[10] Wang Xu. A2/0-MBR Application Research of the Treatment of Urban Sewage. Xi'an, Xi'an University of Architecture and Technology, 2011,p156 168. 